\title{
The effect of loading density of nickel-cobalt sulfide arrays on their cyclic stability and rate performance for supercapacitors
}

\author{
Renzhe Wang, Yazi Luo, Zhi Chen, Ming Zhang* and Taihong Wang*
}

\begin{abstract}
Nickel-cobalt sulfide arrays with different loading densities were fixed on nickel foam via a facile hydrothermal method in ethanol. Their loading densities could be easily adjusted via changing the amount of reactants. It was found that the nickel-cobalt sulfide arrays on $\mathrm{Ni}$ foam with moderate loading density showed excellent electrochemical performance for supercapacitors. The best sample not only exhibited an outstanding areal capacitance of $4.84 \mathrm{~F} \mathrm{~cm}^{-2}$ at 10 $\mathrm{mA} \mathrm{cm} \mathrm{cm}^{-2}$ but also showed the best cycle stability and rate performance compared with the samples with other loading densities. Remarkably, this method to control the loading densities of nickel-cobalt sulfide on nickel foam may provide a new strategy for the investigation of other nanoarrays on various substrates for catalysts and lithium-ion batteries other than supercapacitors.
\end{abstract}

Keywords: loading density, nickel-cobalt sulfide arrays, supercapacitors

\section{INTRODUCTION}

Supercapacitor devices have been divided into the electrical double-layer capacitors (EDLCs) and pseudocapacitors. EDLCs store charge by adsorption of electrolyte ions onto the surface of electrode materials without requiring redox reactions, so the response to changes in potential is rapid and leads to high power. Pseudocapacitors, also called electrochemical capacitors, store charge by undergoing reversible redox reactions at or near the surface of the electrode material. Compared with the EDLCs, pseudocapacitors can obtain higher energy density and capacitance owing to the reversible redox processes [1-6]. In recent years, numerous efforts have been devoted to developing various electrode materials for pseudocapacitors $[7,8]$.
Among them, many research efforts have been devoted to the development of transition-metal sulfides because of their excellent electrochemical properties, for example the high specific capacitance [9-12]. Especially, ternary $\mathrm{Ni}$-Co sulfides have attracted much attention as excellent electrode materials in pseudocapacitors with higher electrochemical activity and higher capacitance than mono-metal sulfides [13-16]. Recently, Wan and co-workers [17] fabricated a novel 3D $\mathrm{NiCo}_{2} \mathrm{~S}_{4}$ nanotube@Ni-Mn layered double hydroxide arrays in situ grown on graphene sponge hierarchical network architectures, which exhibited a specific capacitance $1.74 \mathrm{~F} \mathrm{~cm}^{-2}$ at $1 \mathrm{~mA} \mathrm{~cm}^{-2}$, and $1.27 \mathrm{~F}$ $\mathrm{cm}^{-2}$ maintained at $10 \mathrm{~mA} \mathrm{~cm}^{-2}$. Ding and co-workers [18] grew hierarchical $\mathrm{NiCo}_{2} \mathrm{~S}_{4} @ \mathrm{NiCo}_{x} \mathrm{~S}_{y}$ core/shell nanoarrays on carbon cloth. After 1500 cycles, $\mathrm{NiCo}_{2} \mathrm{~S}_{4} @ \mathrm{NiCo}_{x} \mathrm{~S}_{y}$ nanoarrays remained $77 \%$ retention of the original areal capacitance $\left(3.5 \mathrm{~F} \mathrm{~cm}^{-2}\right)$ at current density of $10 \mathrm{~mA} \mathrm{~cm}^{-2}$. $\mathrm{Xu}$ and co-workers [19] synthesized the hollow Ni-Co sulfide nanoboxes with tunable compositions by using a low-temperature wetchemical method. The $\mathrm{NiCo}_{2} \mathrm{~S}_{4}$ electrode exhibited a capacitance retention of $88.2 \%$ at 5 $\mathrm{A} \mathrm{g}^{-1}$ after 4,000 cycles.

However, does the different loading density of active materials have great effect on the electrochemical properties of the electrode? In the premise of ensuring specific surface area, does a higher loading density of the active material ensure the better electrochemical performances? Cai and co-workers [13] constructed $\mathrm{NiCo}_{2} \mathrm{~S}_{4}$ nanotube arrays on $\mathrm{Ni}$ foam with the mass loading around $7.5 \mathrm{mg} \mathrm{cm}^{-2}$. But after 2,000 cycles at a current density of $60 \mathrm{~mA} \mathrm{~cm}^{-2}$, the electrode capacitance only resulted in $79.3 \%$ retention. Mei

Key Laboratory for Micro-Nano Optoelectronic Devices of Ministry of Education, School of Physics and Electronics, State Key Laboratory for Chemo/Biosensing and Chemometrics, Hunan University, Changsha 410082, China

*Corresponding authors (emails: zhangming@hnu.edu.cn (Zhang M); thwang@hnu.edu.cn (Wang T)) 
and co-workers [14] synthesized mushroom-like $\mathrm{CoNi}_{2} \mathrm{~S}_{4}$ with multidimensional hierarchical arrays on $\mathrm{Ni}$ foam with the mass loading around $2.1 \mathrm{mg} \mathrm{cm}^{-2}$. And after 3,000 cycles at a current density of $20 \mathrm{~mA} \mathrm{~cm}{ }^{-2}$, the electrode capacitance still resulted in $80.9 \%$ retention. Moreover, Tang and co-workers [20] obtained the sandwiched lamellar hybrids, which were ultrathin-layered polypyrrole (PPy) attached $\mathrm{MoS}_{2}$ monolayers with controllable thickness for supercapacitors by varying the amount of pyrrole monomers to $\mathrm{MoS}_{2}$ monolayers in polymerization process. Besides, they indicated that only under a moderate ratio of PPy to $\mathrm{MoS}_{2}$, one can obtain the desirable capacitance. As for the method of synthesizing materials, it is still important and significant to explore the effect of different loading densities of the active materials on the electrochemical performance [21-23].

In this work, four groups of different amounts of reaction materials were used to grow nickel-cobalt sulfide arrays on $\mathrm{Ni}$ foam with the same size separately via a facile hydrothermal method in ethanol. The total amounts of reaction materials were different among the groups, but the proportions of each reaction materials in these groups were the same. Four groups of the nickel-cobalt sulfide arrays were investigated as the pseudocapacitors electrode materials. We found that the amount of reaction materials directly related to the loading density of the active materials on the electrode. Besides, a larger amount of reaction materials corresponded to a larger unit area loading density on the electrode $[24,25]$. However, neither oversized loading density nor minimum loading density did have good electrochemical characteristics. Interestingly, only under a moderate range of loading density on the electrode, one can obtain the desirable cycle stability and rate performance and other electrochemical properties. In addition, because the active materials were grown on the substrate directly, it can guarantee strong adhesion and good electrical contact with the current collector. Furthermore, the electrode design did not use conducting additives or polymer adhesive, which can make full use of the electrode materials [26,27]. Impressively, our result showed that such nickel-cobalt sulfide arrays electrode with moderate loading density of active materials would obtain excellent electrochemical performance for supercapacitors.

\section{EXPERIMENTAL SECTION}

\section{Materials synthesis}

All reagents in this study were of analytical grade and were used without purifying process. The Ni foam substrates were cleaned with acetone, ethanol and deionized water in an ultrasound bath beforehand. Cobalt(II) acetate tetrahydrate and thioacetamide (TAA) in certain ratio were dissolved in $35 \mathrm{~mL}$ ethanol as solvent with stirring. Subsequently, the prepared solution was transferred to the Teflon-lined stainless steel autoclave $(50 \mathrm{~mL})$ and the cleaned nickel foam in certain size was immersed in the solution as a substrate. The autoclave was sealed and maintained at $140^{\circ} \mathrm{C}$ for $11 \mathrm{~h}$. Lastly, the $\mathrm{Ni}$ foam was taken out and cleaned by sonication for $1 \mathrm{~min}$ with the power of 40 percent, then dried in a vacuum drying oven. To investigate the effect of loading density of the final products, cobalt(II) acetate and TAA in different amounts were used for the synthesis on $\mathrm{Ni}$ foam, severally named as S1 (1:4, mmol), S1.5 (1.5:6, mmol), S2 (2:8, mmol) and S3 $(3: 12, \mathrm{mmol})$.

\section{Materials characterization}

The microstructure and morphology of the composites were characterized using scanning electron microscopy (SEM) (Hitachi S4800) and transmission electron microscopy (TEM) (JEOL 2010) which was operated at an accelerating voltage of $200 \mathrm{kV}$. The crystal structure of the samples was characterized by X-ray diffraction $(\mathrm{XRD}, \mathrm{Cu}$ $\mathrm{K}_{\alpha}$ ) with a SIEMENS D5000 X-ray diffractometer.

\section{Electrochemical measurements}

The electrochemical measurements of the four nickelcobalt sulfide arrays groups were carried out in a three-electrode system using aqueous solution of $3 \mathrm{~mol} \mathrm{~L}^{-1} \mathrm{NaOH}$ as the electrolyte. The measurements were conducted with a CHI660E electrochemical workstation (Chenhua, Shanghai). The as-prepared nickel-cobalt sulfide arrays were directly used as the working electrodes in free of binders. The reference electrode was a standard calomel electrode (SCE) and a platinum plate was used as a counter electrode. Voltage windows of cyclic voltammograms (CV) measurements were in the range of 0 to $0.7 \mathrm{~V}$. The electrochemical impedance spectroscopy (EIS) measurements were performed based their different open circuit potentials in a frequency range from $0.01 \mathrm{~Hz}$ to $100 \mathrm{kHz}$. The areal and specific capacitances $(C)$ were calculated using the following equations $[28,29]$ :

$$
C=\frac{I t}{S V} \text { and } C=\frac{I t}{m \mathrm{~V},}
$$

where $C\left(\mathrm{~F} \mathrm{~cm}^{-2}\right.$ or $\left.\mathrm{F} \mathrm{g}^{-1}\right)$ was the capacitance, $I(\mathrm{~A})$, the discharge current, $t(\mathrm{~s})$, the discharge time, and $S\left(\mathrm{~cm}^{2}\right)$, the area of the electrode, $V(\mathrm{~V})$, the potential window, $m$ (g), the mass of the active materials on the electrode. 


\section{RESULTS AND DISCUSSION}

The nickel-cobalt sulfide arrays were synthesized via a onestep hydrothermal method (shown in Fig. 1), where the Ni foam functioned as the nickel source. With the addition of cobalt(II) acetate and TAA, the $\mathrm{pH}$ value of the solution turned below 7 due to the hydrolysis of $\mathrm{Co}^{2+}$. Subsequently, $\mathrm{Ni}$ foam was dissolved in the dilute acid environment and partly converted to divalent nickel $\left(\mathrm{Ni}^{2+}\right)$ on the surface. The obtained $\mathrm{Ni}^{2+}$ would react with $\mathrm{Co}^{2+}$ and TAA to form final nickel-cobalt sulfide arrays on the Ni foam. The SEM images of the corresponding growth process were provided in the Supplementary information (Fig. S1). With the varying additive amounts of cobalt(II) acetate and TAA, different loading densities of final products were harvested, namely S1 $\left(3.1 \mathrm{mg} \mathrm{cm}^{-2}\right), \mathrm{S} 1.5\left(4.5 \mathrm{mg} \mathrm{cm}{ }^{-2}\right), \mathrm{S} 2(5.5 \mathrm{mg}$ $\left.\mathrm{cm}^{-2}\right)$, and $\mathrm{S} 3\left(6.7 \mathrm{mg} \mathrm{cm}^{-2}\right)$. The detailed method of calculating the mass of the active materials was provided in the Supplementary information.

The morphology and the structure of the nickel-cobalt sulfide arrays were characterized by SEM. Figs $2 \mathrm{a}-\mathrm{d}$ show the low magnification SEM images of the four samples respectively. It is clearly seen that all the electrode materials exhibit the structure of the nanorod arrays. With the increased amount of reaction materials, the length and the thickness of the nanorods increase as well. Figs $2 \mathrm{e}$ and $\mathrm{f}$ show the high magnification SEM images of S1.5 and S3 nickel-cobalt sulfide arrays respectively. The diameters of S1.5 nanorods are about $220 \mathrm{~nm}$. And the diameters of
S3 nanorods are about $580 \mathrm{~nm}$. In the area of $2 \mu \mathrm{m}^{2}, \mathrm{~S} 1.5$ grew about 14 nanorods, and S3 grew about 11 nanorods. With the increased amount of reaction materials, the loading density of S3 is much larger than that of S1.5. Obviously, the structure of nanorod arrays directly deposited on the $\mathrm{Ni}$ foam can not only reduce the loss of ohm but also offer a high specific surface area. In addition, the structure also increased the contact area between the electrolyte and the electrode material and contributed to the infiltration of the electrolyte, which can make full use of the electrode materials $[30,31]$. Moreover, some sheets structure is closely combined to the nanorods arrays as shown in the SEM images (Figs 2e and f). This structure can make the nickel-cobalt sulfide arrays steadier during the process of redox reaction $[32,33]$. Furthermore, TEM observations were carried out to further study the structure of the nickel-cobalt sulfide arrays. Figs $3 a$ and $b$ show the TEM images of S1.5 scraped off from the Ni foam by ultrasonic treatment. The nanorod structure is clearly observed, which agrees well with the SEM images in Fig. 2. Meanwhile, because of the sheets structure closely combined to the nanorods, the space between the arrays is abundantly utilized, forming a high specific surface area. In addition, the lattice fringes shown in Fig. 3c can be indexed to the (400) and (440) crystal planes of $(\mathrm{NiCo})_{3} \mathrm{~S}_{4}$. Moreover, Fig. $3 \mathrm{~d}$ shows the XRD pattern of S1.5. All of the diffraction peaks can be indexed to $(\mathrm{NiCo})_{3} \mathrm{~S}_{4}$ and $\mathrm{Ni}_{3} \mathrm{~S}_{2}$ (JCPDS, No. 2-788 and No. 44-1418). The energy-dispersive $\mathrm{X}$-ray spectroscopy element analysis

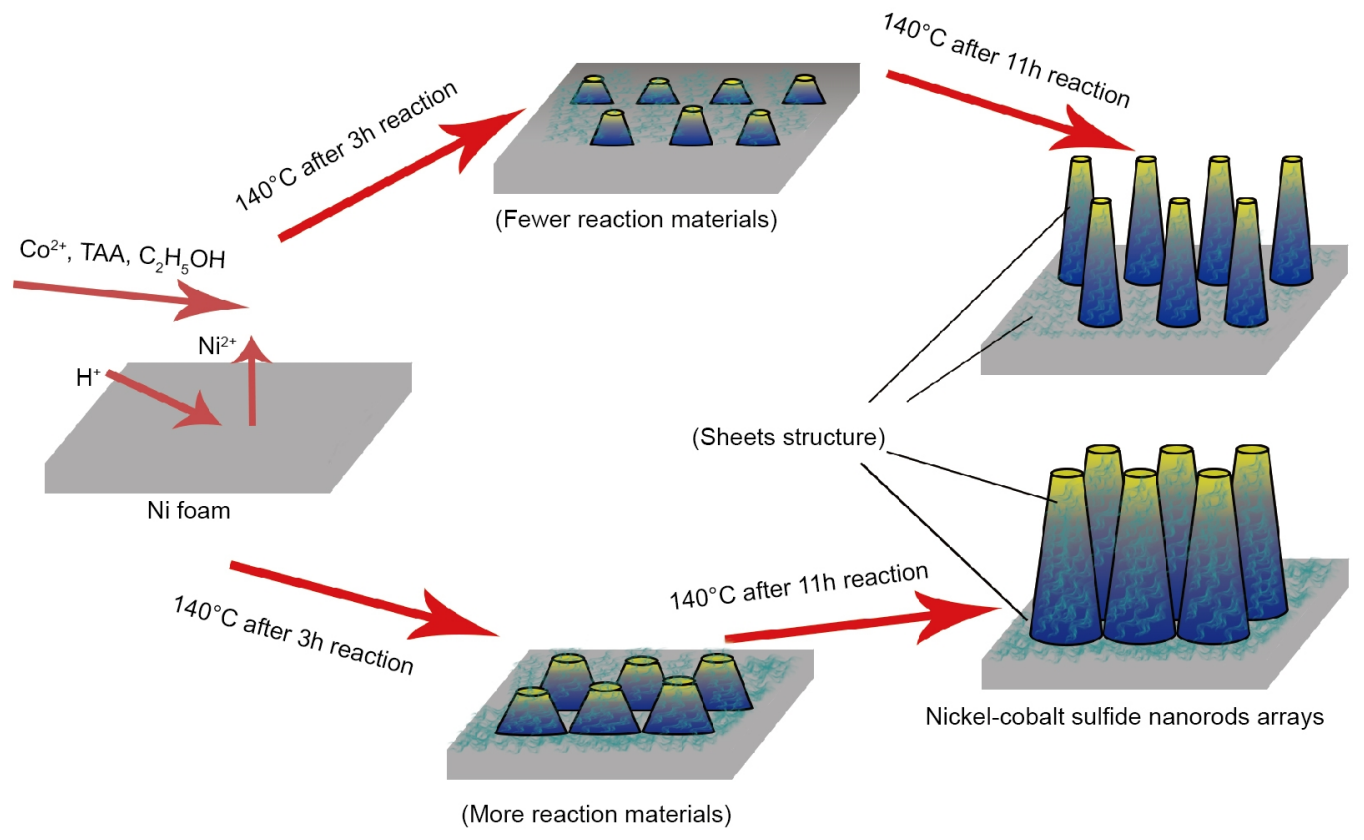

Figure 1 Schematic illustration of the growth of nickel-cobalt sulfide arrays on Ni foam. 

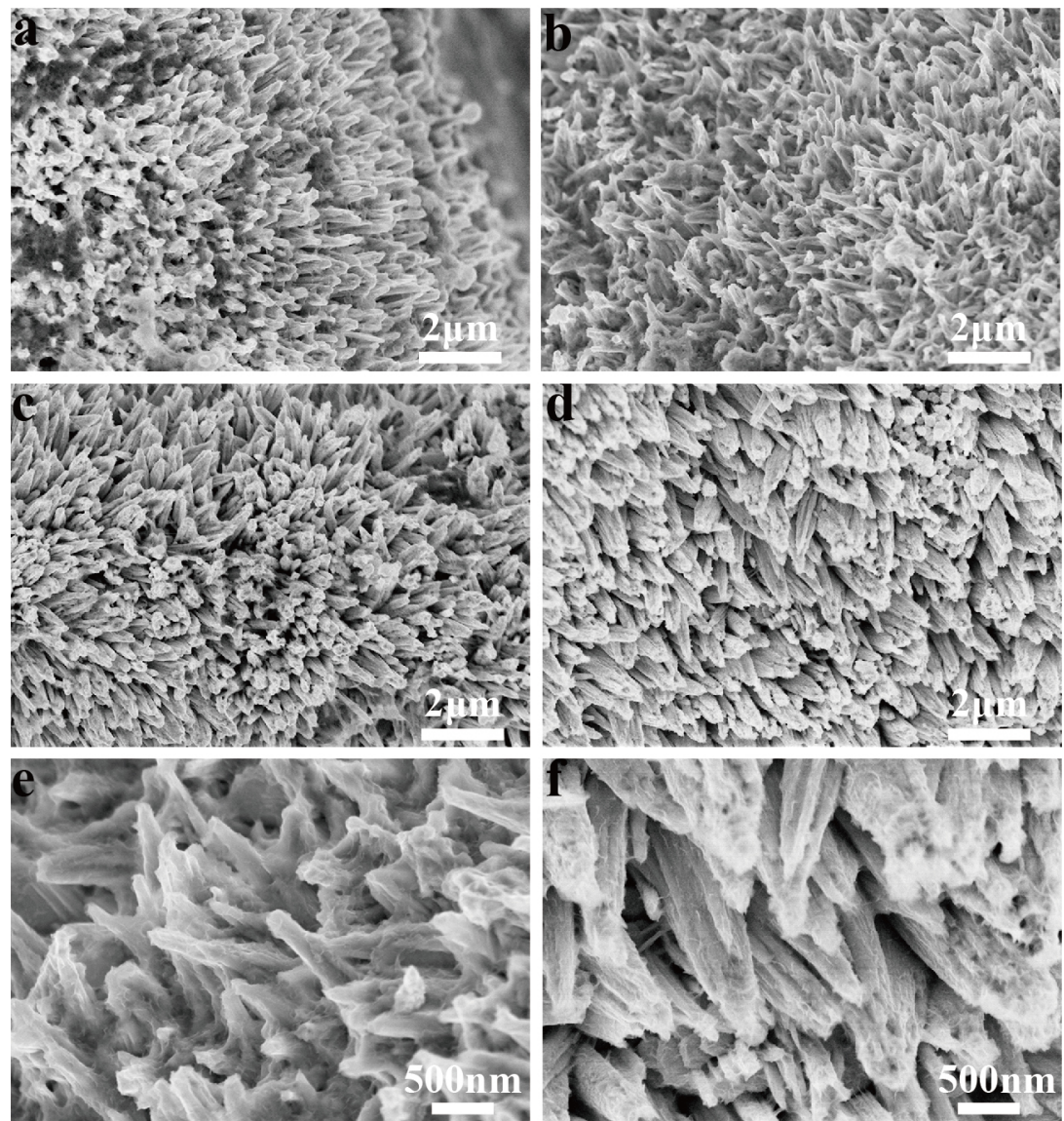

Figure 2 SEM images of nickel-cobalt sulfide arrays on nickel foam (a) S1; (b) S1.5; (c) S2; (d) S3; (e and f) the high magnification images of the S1.5 and S3 nickel-cobalt sulfide arrays.
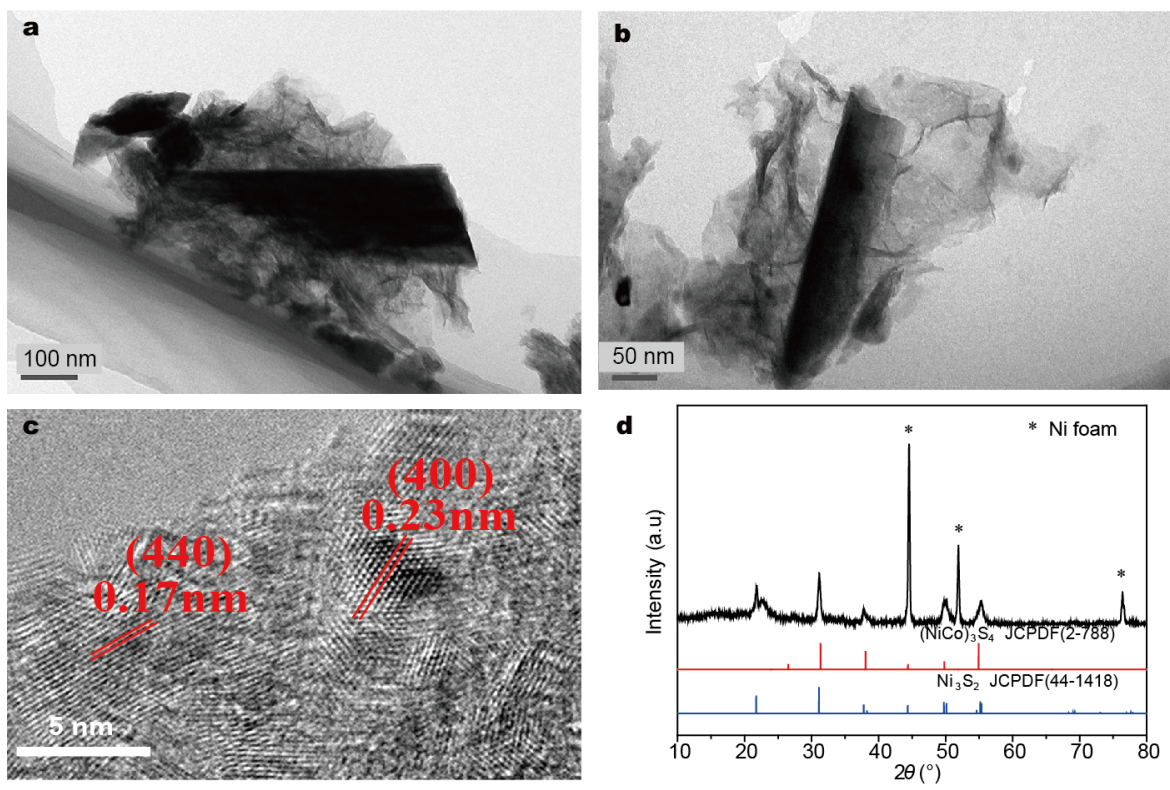

Figure 3 (a, b) TEM images, (c) HRTEM image and (d) XRD pattern of S1.5 nickel-cobalt sulfide arrays. 
of the sample S1.5 (Fig. S2) confirms the existence of Co. Moreover, XRD patterns of other three samples are provided in the Supplementary information (Fig. S4) and they also can match the peaks of the $(\mathrm{CoNi})_{3} \mathrm{~S}_{4}$ (JCPDS No. 2-788) and $\mathrm{Ni}_{3} \mathrm{~S}_{2}$ (JCPDS No. 44-1418).
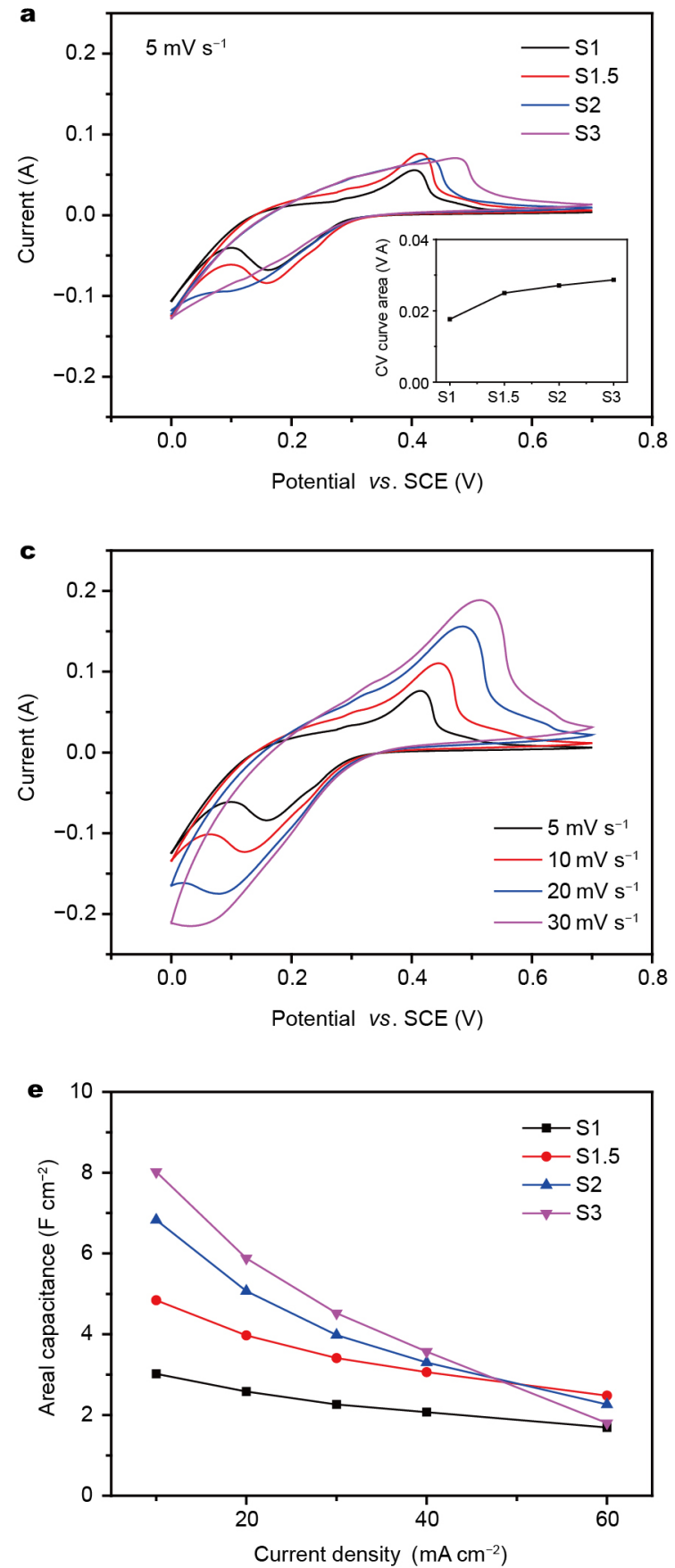

To characterize the electrochemical properties of the as-prepared nickel-cobalt sulfide arrays, $\mathrm{CV}$ were tested in $3 \mathrm{~mol} \mathrm{~L}^{-1} \mathrm{NaOH}$ aqueous electrolyte [34]. Fig. 4a shows the CV comparison of the four nickel-cobalt sulfide arrays electrodes with different loading densities recorded at a
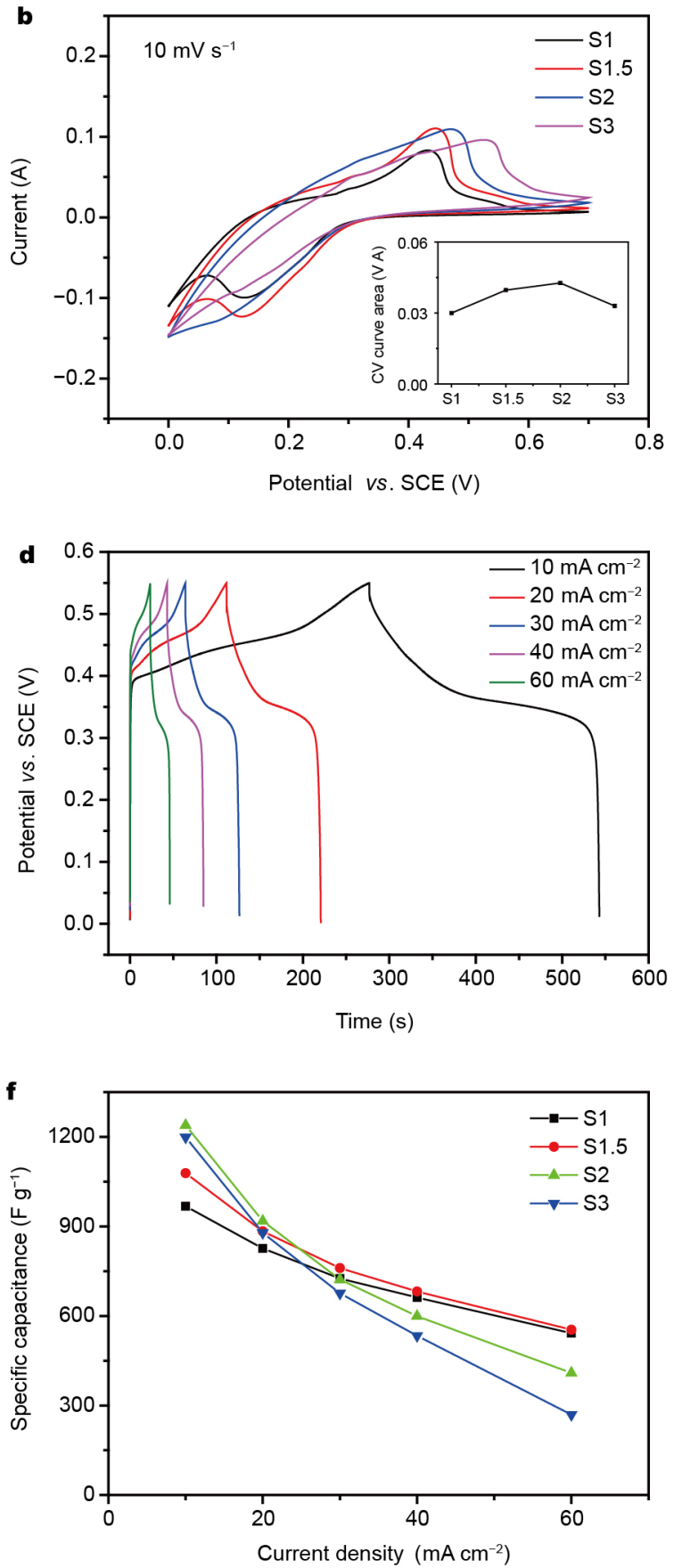

Figure 4 (a) CV curves of the four groups of nickel-cobalt sulfide arrays electrodes at a scan rate of $5 \mathrm{mV} \mathrm{s}^{-1}$; (b) CV curves of the four groups of nickel-cobalt sulfide arrays electrodes at a scan rate of $10 \mathrm{mV} \mathrm{s}^{-1}$; (c) CV curves of S1.5 at various scan rates; (d) galvanostatic current charge/discharge curves of S1.5 at different current densities; (e and f) current density dependence of the areal capacitance and specific capacitance of the four groups of nickel-cobalt sulfide arrays electrodes. 
scan rate of $5 \mathrm{mV} \mathrm{s}^{-1}$. Obviously, with increasing the loading density (from S1 to S3), CV curve integral area of the nickel-cobalt sulfide arrays electrodes is becoming larger and larger (Fig. 4a inset), indicating that at a low scan rate, the greater the loading density, the higher electrochemical activity of the electrode. However, at a scan rate of $10 \mathrm{mV}$ $\mathrm{s}^{-1}$, the CV curve area of S3 is smaller than expected. Fig. $4 \mathrm{~b}$ inset shows that the CV curve integral area of S3 $(0.033$ $\mathrm{VA}$ A) is even smaller than that of S2 $(0.0427 \mathrm{~V} \mathrm{~A})$. This phenomenon indicates that with the increasing scan rates, the more loading density, the more the electrochemical activity is limited by the scan rate, which may be attributed to the dependence of redox reactions on the insertion-deinsertion of protons from the electrolyte. At lower scan rates, all the diffusion of ions from the electrolyte can undergo redox reactions with the active materials on the electrode $[14,35]$. Whereas with the increaseing scan rate, the effective interaction between the electrode and the ions was greatly reduced. Moreover, internal active materials of electrodes, especially those covered with outer active materials, are rather difficult to react with the electrolyte, which may lead to a lower electrochemical activity. Accordingly, S1.5 exhibited satisfactory electrochemical performance. The $\mathrm{CV}$ peaks of pure Ni foam were very weak (as shown in Fig. S3). So the effect of Ni foam was ignored. Fig. 4c shows the $\mathrm{CV}$ curves of $\mathrm{S} 1.5$ at scan rates from 5 to $30 \mathrm{mV} \mathrm{s}^{-1}$. Clearly, two pairs of redox peaks can be seen as the sweep rates decrease because of the reversible Faradaic redox. The redox peaks in all $\mathrm{CV}$ curves can be attributed to the redox reactions related to $\mathrm{M}-\mathrm{S} / \mathrm{M}-\mathrm{S}-\mathrm{OH}$ and $\mathrm{Ni}_{3} \mathrm{~S}_{2}$, where $\mathrm{M}$ representes $\mathrm{Ni}$ and $\mathrm{Co}$ ions based on the following reactions [10,36-38]:

$$
\begin{aligned}
\mathrm{CoS}+\mathrm{OH}^{-} & \leftrightarrow \mathrm{CoSOH}+\mathrm{e}^{-} \\
\mathrm{CoSOH}+\mathrm{OH}^{-} & \leftrightarrow \mathrm{CoSO}+\mathrm{H}_{2} \mathrm{O}+\mathrm{e}^{-} \\
\mathrm{NiS}+\mathrm{OH}^{-} & \leftrightarrow \mathrm{NiSOH}+\mathrm{e}^{-} \\
\mathrm{Ni}_{3} \mathrm{~S}_{2}+3 \mathrm{OH}^{-} & \leftrightarrow \mathrm{Ni}_{3} \mathrm{~S}_{2}(\mathrm{OH})_{3}+3 \mathrm{e}^{-}
\end{aligned}
$$

To further evaluate the capacitive performance of four nickel-cobalt sulfide arrays electrodes, the galvanostatic charge-discharge measurements were conducted at various current densities ranging from 10 to $60 \mathrm{~mA} \mathrm{~m}^{-2}$. Fig. $4 \mathrm{~d}$ shows the typical charge and discharge curves of S1.5 at different current densities with a potential window of 0 to $0.55 \mathrm{~V}$. Chronopotentiometry (CP) curves of S1.5 are nearly symmetrical, indicating good reversibility of the redox reactions for the nickel-cobalt sulfide arrays electrode. Moreover, the areal capacitance and specific capacitance of the four nickel-cobalt sulfide arrays electrodes at different current densities can be calculated based on the CP curves and plotted in Fig. 4 e and f. Obviously, with the increasing current density, the greater loading density of the active material in the unit area, the worse rate stability is. Figs $4 \mathrm{e}$ and $\mathrm{f}$ show that though $\mathrm{S} 3$ exhibited the capacitance of $8.02 \mathrm{~F} \mathrm{~cm}^{-2}\left(1199.1 \mathrm{~F} \mathrm{~g}^{-1}\right)$ at $10 \mathrm{~mA} \mathrm{~cm}^{-2}$, but it delivered the capacitance of $1.8 \mathrm{~F} \mathrm{~cm}^{-2}\left(269.1 \mathrm{~F} \mathrm{~g}^{-1}\right)$ when the current density reached $60 \mathrm{~mA} \mathrm{~cm}^{-2}$. Similarly, S2 exhibited the capacitance of $6.83 \mathrm{~F} \mathrm{~cm}^{-2}\left(1238.8 \mathrm{~F} \mathrm{~g}^{-1}\right)$ at $10 \mathrm{~mA} \mathrm{~cm}^{-2}$, but $2.26 \mathrm{~F} \mathrm{~cm}^{-2}\left(409.1 \mathrm{~F} \mathrm{~g}^{-1}\right)$ at $60 \mathrm{~mA} \mathrm{~cm}^{-2}$. Their rate performances declined seriously. Besides, $\mathrm{S} 1$ exhibited lower capacitance of $3.02 \mathrm{~F} \mathrm{~cm}^{-2}\left(967.4 \mathrm{~F} \mathrm{~g}^{-1}\right)$ at $10 \mathrm{~mA} \mathrm{~cm}^{-2}$ and $1.69 \mathrm{~F} \mathrm{~cm}^{-2}\left(542 \mathrm{~F} \mathrm{~g}^{-1}\right)$ at $60 \mathrm{~mA} \mathrm{~cm}^{-2}$. Impressively, $\mathrm{S} 1.5$ delivered good capacitance of $4.84 \mathrm{~F} \mathrm{~cm}^{-2}\left(1078.4 \mathrm{~F} \mathrm{~g}^{-1}\right)$ at $10 \mathrm{~mA} \mathrm{~cm}^{-2}$, even at $60 \mathrm{~mA} \mathrm{~cm}^{-2}$, the capacitance of 2.48 $\mathrm{F} \mathrm{cm}^{-2}\left(554 \mathrm{~F} \mathrm{~g}^{-1}\right)$ maintained. $\mathrm{Xu}$ and co-worker synthesized the hollow Ni-Co sulfide nanoboxes with tunable compositions which exhibited the capacitance of $1588 \mathrm{~F} \mathrm{~g}^{-1}$ at $2 \mathrm{~A} \mathrm{~g}^{-1}$ and $1098 \mathrm{~F} \mathrm{~g}^{-1}$ at $20 \mathrm{~A} \mathrm{~g}^{-1}$ [19]. Compared with other groups, S1.5 not only obtained good capacitance at low current density, but also maintained a preferable rate stability and capacitance at high current density. These proved that there comes to be an optimum loading density of active materials.

To further evaluate the electrochemical behaviors of the nickel-cobalt sulfide arrays electrodes, an EIS measurement was performed in a frequency ranging from 0.01 $\mathrm{Hz}$ to $100 \mathrm{kHz}$ as shown in Fig. 5a. The four groups of samples all show the similar form with a sloping curve at lower frequency and a semicircle at a higher frequency region. The impedance spectra form curve along the axis at a lower frequency, and the slope of the curve shows the Warburg impedance (W) which represents the electrolyte diffusion in the electrode and proton diffusion in host materials $[39,40]$. With the decreased amount of reaction materials, smaller loading density nickel-cobalt sulfide arrays electrodes show the more ideal curve along the axis, which demonstrates that they have lower diffusion resistance, because the smaller loading density can facilitate the $\mathrm{OH}^{-}$to the entrance of arrays. At the high frequency (Fig. 5a inset), the intersection of the curve at the axis indicates the bulk resistance [34]. The inset shows that larger loading density may produce larger bulk resistance of electrochemical system. Moreover the semicircle diameter reflects the charge-transfer resistance $\left(R_{\mathrm{ct}}\right)$. S1.5 and S2 nickel-cobalt sulfide arrays electrodes have smaller semicircle compared with the others. The moderate loading density may improve the charge-transfer process at the working electrode-electrolyte interface. So, the S1.5 and 
S2 nickel-cobalt sulfide arrays electrodes had the smaller $\mathrm{R}_{\mathrm{c} t} \mathrm{~S}$ which can provide more convenient path ways for the ion and electron transport [41].

The good electrochemical property of the nickel-cobalt sulfide arrays electrodes were further confirmed by galvanostatic charge-discharge cycling test at $20 \mathrm{~mA} \mathrm{~cm}{ }^{-2}$ (Fig. 5b). For S1 nickel-cobalt sulfide arrays electrode, it exhibited $2.53 \mathrm{~F} \mathrm{~cm}^{-2}$ of the original areal capacitance and after 3000 cycles it maintained $1.91 \mathrm{~F} \mathrm{~cm}^{-2}$, remaining $75.3 \%$ capacitance retention. Besides, S1.5 nickel-cobalt sulfide arrays electrode exhibited $3.90 \mathrm{~F} \mathrm{~cm}^{-2}$ of the original areal capacitance and it maintained $3.45 \mathrm{~F} \mathrm{~cm}^{-2}$ after 3000 cycles, remaining $88.4 \%$ capacitance retention. Ding and co-worker grew hierarchical $\mathrm{NiCo}_{2} \mathrm{~S}_{4} @ \mathrm{NiCo}_{x} \mathrm{~S}_{y}$ core/shell nanoarrays on carbon cloth. After 1500 cycles, $\mathrm{NiCo}_{2} \mathrm{~S}_{4} @ \mathrm{NiCo}_{x} \mathrm{~S}_{y}$ nanoarrays remained 77\% retention of the original areal capacitance $\left(3.5 \mathrm{~F} \mathrm{~cm}^{-2}\right)$ at current density of $10 \mathrm{~mA} \mathrm{~cm}^{-2}$ [18]. And the S2 nickel-cobalt sulfide arrays electrode exhibited $4.95 \mathrm{~F} \mathrm{~cm}^{-2}$ of the original areal capacitance and after 3000 cycles it maintained $4.10 \mathrm{~F} \mathrm{~cm}^{-2}$, remaining $82.9 \%$ capacitance retention. At last, the sample of S3 nickel-cobalt sulfide arrays electrode exhibited 5.67 $\mathrm{F} \mathrm{cm}^{-2}$ of the original areal capacitance and it maintained $4.16 \mathrm{~F} \mathrm{~cm}^{-2}$ after 3000 cycles, remaining only $73.3 \%$ capacitance retention. Fig. $5 \mathrm{~b}$ shows that only under a moderate loading density of nickel-cobalt sulfide arrays electrode which would obtain good cycling performance. For the nickel-cobalt sulfide arrays electrode with smaller loading density like sample of S1, it has less total capacitance. At the same current density, not completely reversible redox reaction may have more impact on its cycle stability compared with the others. Meanwhile, for the nickel-cobalt sulfide arrays electrode with larger loading density like S3, its arrays structure may more easily collapse, resulting the fading of the areal capacitance during the long-duration cycle with the redox reaction $[13,14]$. Moreover, Figs $6 a-d$ are SEM images of group S1.5 and S3 after 3000 cycles of charge and discharge at $20 \mathrm{~mA} \mathrm{~cm}{ }^{-2}$ respectively. It is clearly observed that nickel-cobalt sulfide arrays structure of S3 collapses more seriously than arrays structure of S1.5 after 3000 cycles of charge and discharge. Many cracks appear obviously in the arrays of S3. This may also because the loading density of active material on the electrode of S3 is too large. And structure of S3 is more likely to collapse during the redox reaction. This phenomenon can also support our ideas that the loading density on unit area of the electrode is not the bigger the better.

The good electrochemical performance of the nickel-cobalt sulfide arrays electrodes can be ascribed to the following features of the electrodes. Firstly, the nickel-cobalt sulfide arrays have grown directly on $\mathrm{Ni}$ foam, which can guarantee good electrical contact with the current collector and strong adhesion. Meanwhile, the electrode design did not use conducting additives and polymer adhesive, which can make full use of the electrode materials [26,27]. Secondly, with the appropriate loading density, the active materials can combine more closely with the electrolyte, and facilitate the supply of $\mathrm{OH}^{-}$to the entrance of arrays. Also, it can decrease the internal materials which cannot be fully involved in the reaction. Thirdly, under the premise of ensuring adequate capacitance, the moderate loading density can ensure the more stable electrodes arrays structure reducing the capacitance loss caused by the collapsing of the structure during the
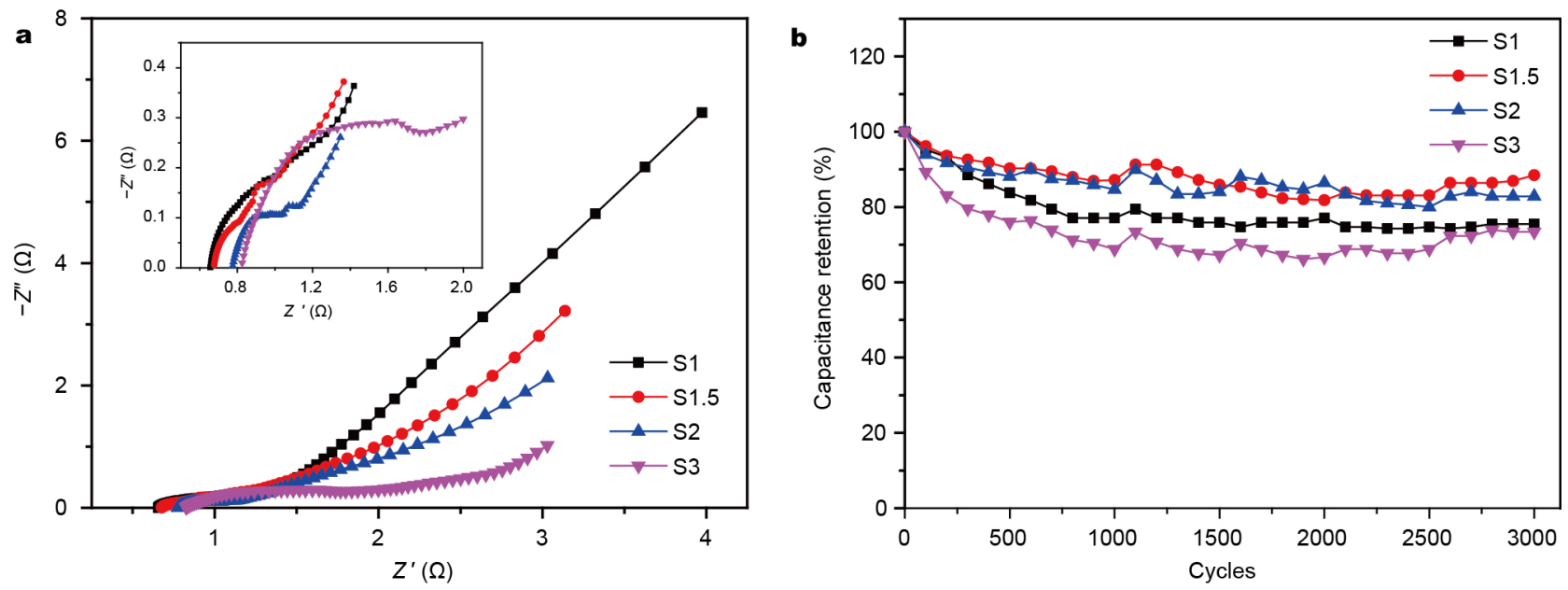

Figure 5 (a) Impedance Nyquist plots of four groups of nickel-cobalt sulfide arrays electrodes at open circuit potential; (b) cycling performance of the four groups of nickel-cobalt sulfide arrays electrodes at current densities of $20 \mathrm{~mA} \mathrm{~cm}^{-2}$. 

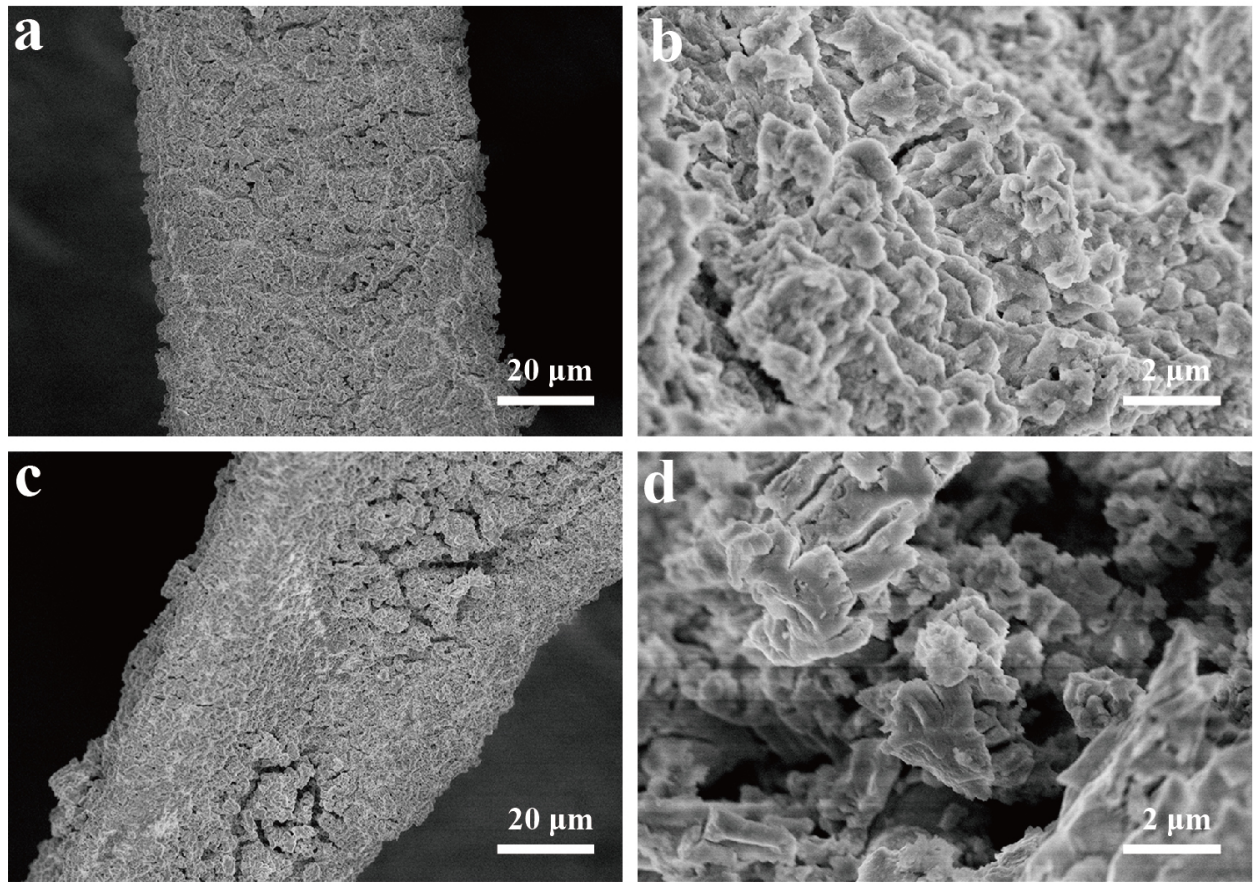

Figure 6 (a and b) SEM images of the group S1.5 nickel-cobalt sulfide arrays on nickel foam after 3000 cycles of charge/discharge at $20 \mathrm{~mA} \mathrm{~cm}{ }^{-2}$; $(\mathrm{c}$ and d) SEM images of the group S3 nickel-cobalt sulfide arrays on nickel foam after 3000 cycles of charge/discharge at $20 \mathrm{~mA} \mathrm{~cm}{ }^{-2}$.

redox reaction.

\section{CONCLUSIONS}

In summary, four groups of reaction materials with different amounts have been used to grow nickel-cobalt sulfide arrays on $\mathrm{Ni}$ foam with the same size separately via a facile hydrothermal method in ethanol. With the increased amount of reaction materials, the loading density of the active materials on the electrode increased. Remarkably, we found that only with moderate loading density of nickel-cobalt sulfide arrays on Ni foam would obtain excellent electrochemical performance for supercapacitors. In this work, the S1.5 nickel-cobalt sulfide arrays electrode exhibits more desirable electrochemical performance compared with sample with other loading densities. Besides, S1.5 nickel-cobalt sulfide arrays electrode exhibits $3.90 \mathrm{~F}$ $\mathrm{cm}^{-2}$ of the original areal capacitance at $20 \mathrm{~mA} \mathrm{~cm}^{-2}$ and it maintained $3.45 \mathrm{~F} \mathrm{~cm}^{-2}$ after 3000 cycles, remaining $88.4 \%$ capacitance retention. Moreover, with the appropriate loading density, the active materials can combine more closely with the electrolyte, and decrease the internal materials which cannot be fully involved in the reaction. Also, the moderate loading density can ensure the more stable electrode arrays structure reducing the capacitance loss caused by the collapsing of the structure during the redox reaction. In light of the superior electrochemical properties and the convenient and cost-efficient synthesis, such nickel-cobalt sulfide arrays electrode with moderate loading density of active materials would provide great potential for high-performance supercapacitors in future.

\section{Received 30 May 2016; accepted 6 August 2016;} published online 23 August 2016

1 Miller JR, Simon P. Electrochemical capacitors for energy management. Science, 2008, 321: 651-652

2 Candelaria SL, Garcia BB, Liu D, et al. Nitrogen modification of highly porous carbon for improved supercapacitor performance. J Mater Chem, 2012, 22: 9884-9889

3 Simon P, Gogotsi Y, Dunn B. Where do batteries end and supercapacitors begin? Science, 2014, 343: 1210-1211

4 Wu ZS, Feng X, Cheng HM. Recent advances in graphene-based planar micro-supercapacitors for on-chip energy storage. Natl Sci Rev, 2014, 1: 277-292

5 Candelaria SL, Uchaker E, Cao G. Comparison of surface and bulk nitrogen modification in highly porous carbon for enhanced supercapacitors. Sci China Mater, 2015, 58: 521-533

6 Zhang X, Zhang H, Lin Z, et al. Recent advances and challenges of stretchable supercapacitors based on carbon materials. Sci China Mater, 2016, 59: 475-494

7 Luo Y, Zhang $\mathrm{H}$, Wang L, et al. Fixing graphene- $\mathrm{Mn}_{3} \mathrm{O}_{4}$ nanosheets on carbon cloth by a poles repel-assisted method to prepare flexible binder-free electrodes for supercapacitors. Electrochim Acta, 2015, 180: 983-989

8 Lu Z, Wu X, Jiang M, et al. Transition metal oxides/hydroxides nanoarrays for aqueous electrochemical energy storage systems. Sci China Mater, 2014, 57: 59-69

9 Kung CW, Chen HW, Lin CY, et al. CoS acicular nanorod arrays for 
the counter electrode of an efficient dye-sensitized solar cell. ACS Nano, 2012, 6: 7016-7025

$10 \mathrm{Yu} \mathrm{L}$, Zhang $\mathrm{L}$, Wu HB, et al. Formation of $\mathrm{Ni}_{x} \mathrm{Co}_{3-x} \mathrm{~S}_{4}$ hollow nanoprisms with enhanced pseudocapacitive properties. Angew Chem, 2014, 126: 3785-3788

11 Yang T, Chen Y, Qu B, et al. Construction of 3D flower-like $\mathrm{MoS}_{2}$ spheres with nanosheets as anode materials for high-performance lithium ion batteries. Electrochim Acta, 2014, 115: 165-169

12 Zhu $\mathrm{C}, \mathrm{Mu} \mathrm{X}$, van Aken PA, et al. Single-layered ultrasmall nanoplates of $\mathrm{MoS}_{2}$ embedded in carbon nanofibers with excellent electrochemical performance for lithium and sodium storage. Angew Chem Int Ed, 2014, 53: 2152-2156

13 Cai D, Wang D, Wang C, et al. Construction of desirable $\mathrm{NiCo}_{2} \mathrm{~S}_{4}$ nanotube arrays on nickel foam substrate for pseudocapacitors with enhanced performance. Electrochim Acta, 2015, 151: 35-41

14 Mei L, Yang T, Xu C, et al. Hierarchical mushroom-like $\mathrm{CoNi}_{2} \mathrm{~S}_{4}$ arrays as a novel electrode material for supercapacitors. Nano Energy, 2014, 3: 36-45

15 Chen $\mathrm{H}$, Jiang J, Zhang L, et al. Highly conductive $\mathrm{NiCo}_{2} \mathrm{~S}_{4}$ urchin-like nanostructures for high-rate pseudocapacitors. Nanoscale, 2013, 5: 8879-8883

16 Li R, Wang S, Huang Z, et al. $\mathrm{NiCo}_{2} \mathrm{~S}_{4} @ \mathrm{Co}(\mathrm{OH})_{2}$ core-shell nanotube arrays in situ grown on Ni foam for high performances asymmetric supercapacitors. J Power Sources, 2016, 312: 156-164

17 Wan $\mathrm{H}$, Liu J, Ruan $\mathrm{Y}$, et al. Hierarchical configuration of $\mathrm{NiCo}_{2} \mathrm{~S}_{4}$ nanotube@Ni-Mn layered double hydroxide arrays/three-dimensional graphene sponge as electrode materials for high-capacitance supercapacitors. ACS Appl Mater Interface, 2015, 7: 15840-15847

18 Ding R, Zhang M, Yao Y, et al. Crystalline $\mathrm{NiCo}_{2} \mathrm{~S}_{4}$ nanotube array coated with amorphous $\mathrm{NiCo}_{x} \mathrm{~S}_{y}$ for supercapacitor electrodes. J Colloid Interface Sci, 2016, 467: 140-147

$19 \mathrm{Xu}$ Y, Gao X, Chu W, et al. Ni-Co sulfide nanoboxes with tunable compositions for high-performance electrochemical pseudocapacitors. J Mater Chem A, 2016, 4: 10248-10253

20 Tang $\mathrm{H}$, Wang J, Yin $\mathrm{H}$, et al. Growth of polypyrrole ultrathin films on $\mathrm{MoS}_{2}$ monolayers as high-performance supercapacitor electrodes. Adv Mater, 2015, 27: 1117-1123

21 Lin T, Chen IW, Liu F, et al. Nitrogen-doped mesoporous carbon of extraordinary capacitance for electrochemical energy storage. Science, 2015, 350: 1508-1513

22 Tang $\mathrm{X}$, Wei $\mathrm{Y}$, Zhang $\mathrm{H}$, et al. The positive influence of graphene on the mechanical and electrochemical properties of $\mathrm{Sn}_{x} \mathrm{Sb}$-graphene-carbon porous mats as binder-free electrodes for $\mathrm{Li}^{+}$storage. Electrochim Acta, 2015, 186: 223-230

23 Wang K, Zhang X, Sun X, et al. Conducting polymer hydrogel materials for high-performance flexible solid-state supercapacitors. Sci China Mater, 2016, 59: 412-420

24 Tang Z, Tang C, Gong H. A high energy density asymmetric supercapacitor from nano-architectured $\mathrm{Ni}(\mathrm{OH})_{2} /$ carbon nanotube electrodes. Adv Funct Mater, 2012, 22: 1272-1278

25 Wang H, Xu Z, Li Z, et al. Hybrid device employing three-dimensional arrays of $\mathrm{MnO}$ in carbon nanosheets bridges battery-supercapacitor divide. Nano Lett, 2014, 14: 1987-1994

26 Jiang J, Li Y, Liu J, et al. Building one-dimensional oxide nanostructure arrays on conductive metal substrates for lithium-ion battery anodes. Nanoscale, 2011, 3: 45-58

27 Jiang J, Li Y, Liu J, et al. Recent advances in metal oxide-based electrode architecture design for electrochemical energy storage. Adv Mater, 2012, 24: 5166-5180
Zhang G, Lou XWD. General solution growth of mesoporous
$\mathrm{NiCo}_{2} \mathrm{O}_{4}$ nanosheets on various conductive substrates as high-performance electrodes for supercapacitors. Adv Mater, 2013, 25: 976-979

29 Zhang GQ, Wu HB, Hoster HE, et al. Single-crystalline $\mathrm{NiCo}_{2} \mathrm{O}_{4}$ nanoneedle arrays grown on conductive substrates as binder-free electrodes for high-performance supercapacitors. Energy Environ Sci, 2012, 5: 9453-9456

30 Lu X, Zeng Y, Yu M, et al. Oxygen-deficient hematite nanorods as high-performance and novel negative electrodes for flexible asymmetric supercapacitors. Adv Mater, 2014, 26: 3148-3155

31 Cao $\mathrm{Y}$, Wei $\mathrm{Z}, \mathrm{He} \mathrm{J}$, et al. a-MnO2 nanorods grown in situ on graphene as catalysts for $\mathrm{Li}-\mathrm{O}_{2}$ batteries with excellent electrochemical performance. Energy Environ Sci, 2012, 5: 9765-9768

32 Tao L, Zai J, Wang $\mathrm{K}$, et al. $\mathrm{Co}_{3} \mathrm{O}_{4}$ nanorods/graphene nanosheets nanocomposites for lithium ion batteries with improved reversible capacity and cycle stability. J Power Sources, 2012, 202: 230-235

33 Zhou W, Cao X, Zeng Z, et al. One-step synthesis of $\mathrm{Ni}_{3} \mathrm{~S}_{2}$ nanorod@Ni(OH $)_{2}$ nanosheet core-shell nanostructures on a three-dimensional graphene network for high-performance supercapacitors. Energy Environ Sci, 2013, 6: 2216-2221

34 Zhou C, Zhang Y, Li Y, et al. Construction of high-capacitance 3D CoO@polypyrrole nanowire array electrode for aqueous asymmetric supercapacitor. Nano Lett, 2013, 13: 2078-2085

35 Wang Q, Liu B, Wang X, et al. Morphology evolution of urchinlike $\mathrm{NiCo}_{2} \mathrm{O}_{4}$ nanostructures and their applications as psuedocapacitors and photoelectrochemical cells. J Mater Chem, 2012, 22: 21647-21653

36 Wan $\mathrm{H}$, Jiang J, $\mathrm{Yu}$ J, et al. $\mathrm{NiCo}_{2} \mathrm{~S}_{4}$ porous nanotubes synthesis via sacrificial templates: high-performance electrode materials of supercapacitors. CrystEngComm, 2013, 15: 7649-7651

37 Huo $\mathrm{H}$, Zhao $\mathrm{Y}, \mathrm{Xu}$ C. $3 \mathrm{D} \mathrm{Ni}_{3} \mathrm{~S}_{2}$ nanosheet arrays supported on $\mathrm{Ni}$ foam for high-performance supercapacitor and non-enzymatic glucose detection. J Mater Chem A, 2014, 2: 15111-15117

38 Xing $\mathrm{Z}$, Chu $\mathrm{Q}$, Ren $\mathrm{X}$, et al. $\mathrm{Ni}_{3} \mathrm{~S}_{2}$ coated $\mathrm{ZnO}$ array for highperformance supercapacitors. J Power Sources, 2014, 245: 463-467

39 Luo $\mathrm{Y}$, Zhang $\mathrm{H}$, Guo $\mathrm{D}$, et al. Porous $\mathrm{NiCo}_{2} \mathrm{O}_{4}$-reduced graphene oxide (rGO) composite with superior capacitance retention for supercapacitors. Electrochim Acta, 2014, 132: 332-337

40 Chen X, Chen X, Zhang F, et al. One-pot hydrothermal synthesis of reduced graphene oxide/carbon nanotube/ $\alpha-\mathrm{Ni}(\mathrm{OH})_{2}$ composites for high performance electrochemical supercapacitor. J Power Sources, 2013, 243: 555-561

41 Zhang $\mathrm{H}$, Chen $\mathrm{Y}$, Wang W, et al. Hierarchical Mo-decorated $\mathrm{Co}_{3} \mathrm{O}_{4}$ nanowire arrays on $\mathrm{Ni}$ foam substrates for advanced electrochemical capacitors. J Mater Chem A, 2013, 1: 8593-8600

Acknowledgments This work was supported by the National Natural Science Foundation of China (51404103, 61376073 and 51574117), Hunan University Fund for Multidisciplinary Developing (2015JCA04) and Fundamental Research Funds for the Central Universities.

Author contributions Wang $\mathrm{R}$ and Zhang $\mathrm{M}$ designed the project. Wang R performed the main experiments. Luo Y participated in the article work, and put forward valuable suggestions. Chen $\mathrm{Z}$ helped with the experiments. Wang $\mathrm{R}$, Zhang $\mathrm{M}$ and Wang $\mathrm{T}$ analyzed the data and wrote the manuscript

Conflict of interest The authors declare that they have no conflict of interest.

Supplementary information Supplementary data are available in the online version of the paper. 


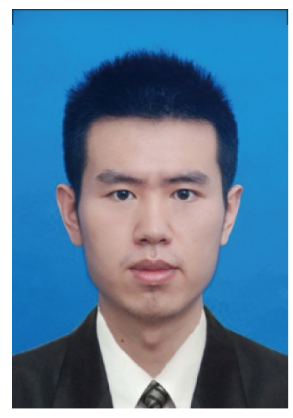

Renzhe Wang is a graduate student at the School of Physics and Electronics, Hunan University. His current research is focused on the nanoscience and nanodevice for energy storage and conversion.

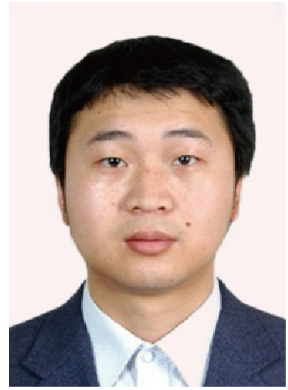

Ming Zhang is an assistant professor in Hunan University since 2012. His research is focused on the design and synthesis of nanocomposites for supercapacitors, lithium ion batteries, and gas sensors. He has published more than 50 papers which have been cited more than 2200 times.

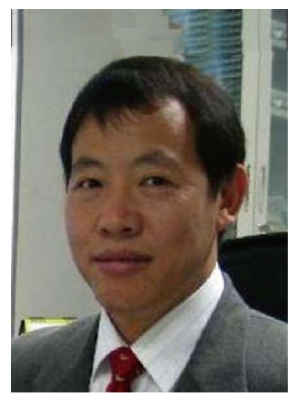

Taihong Wang is a Cheung Kong Professor in Hunan University since 2005. His research interests include ultrasensors, lithium ion batteries, and nanodevices. He has published more than 200 papers, and more than 80 papers were published in the noted Journal of Applied Physics Letters in the field of applied physics. More than 50 items of his patents have been authorized.

\section{镍钴硫阵列电极的负载密度对超级电容器倍率性能及循环稳定性的影响}

王任哲, 罗雅孜, 陈智, 张明*, 王太宏*

摘要 本文以无水乙醇为溶剂通过水热反应在泡沫镍上生长了不同负载密度的镍钴硫阵列. 它们的负载密度可以通过简单方法来调节. 而 且, 通过实验发现, 在泡沫镍上生长负载密度适中的镍钴硫阵列时, 能获得优异的超电容电化学性能. 本实验中, 性能最好的实验组不仅在 $10 \mathrm{~mA} \mathrm{~cm}$ 时表现出了 $4.84 \mathrm{~F} \mathrm{~cm}^{-2}$ 的杰出面电容, 同时也表现出了比其他负载密度实验组更加优异的循环稳定性以及倍率性能. 值得注意 的是, 这种控制镍钴硫阵列负载密度的实验方案, 还能够为除了超电容以外的催化及锂电池研究提供一种将其他纳米阵列长在各种衬基 上的新策略. 